\title{
Accident reconstruction and plume modeling of an unplanned ammonia release
}

\author{
A. Daly ${ }^{1}$, P. Zannetti ${ }^{1} \&$ M. Jennings ${ }^{2}$ \\ ${ }^{1}$ The EnviroComp Institute, Fremont, California, USA \\ ${ }^{2}$ San Jose State University, San Jose, California, USA
}

\begin{abstract}
This paper describes the study we performed in relation to an accidental release of ammonia at a plant in Luling, Louisiana. Our work involved the understanding of the dynamics of the accident, the evaluation of the emission scenario, the computer modeling of the ammonia plume transported by the wind, and the visualization of our results for the purpose of litigation support and presentation to a non-technical audience. The emission scenario was complicated because of a high-velocity jet release and stormy weather conditions. We used emissions and weather data available at the site, in addition to other local weather data. We also used an EPA-approved model to simulate the transport and dispersion of the ammonia cloud and calculate ground-level concentrations of ammonia over the period of concern (a 2-hour interval). We concluded that maximum hourly concentrations of ammonia, beyond the industrial fenceline in the local community, were around $0.20 \mathrm{ppm}$, which is far below existing levels of concern. However, our odor modeling calculations showed that short-term concentrations were potentially larger, and may have reached 5 ppm for very short periods. Our estimated concentrations of ammonia were validated by the locations and times of local odor complaints as well as in-situ measurements. Finally, we visualized the plume by applying a simplified version of our MONTECARLO particle model and creating a computer animation of plume concentrations, in order to illustrate the dynamics of the events to a non-technical audience.
\end{abstract}

Keywords: accident reconstruction, air quality modelling, ISC3, MONTECARLO, plume modeling. 


\section{Introduction}

On September 18, 1998, at about 10:40 AM local time, there was a line rupture in the ammonia production unit at Monsanto Company's facility in Luling, Louisiana. This rupture was quickly discovered and isolated by the plant operators, and the result was an atmospheric release of approximately 2,227 pounds of gaseous ammonia over a period of about 2 hours. The release brought a class action litigation of local residents alleging exposure to air emissions. A law firm retained our services to investigate the accident, develop a model for the release, and visualize the possible concentration impacts at ground level for ammonia.

These tasks first required an estimate of the release rate of ammonia from the fractured pipe. The second step involved the computation of the dispersion of ammonia in the immediate neighbourhood of the release using specialized computer models.

The US Environmental Protection Agency (EPA) has developed and tested air pollution dispersion models (e.g., ISC3 and AERMOD) that are suitable for simulating the dispersion of emissions from various types of sources and the physical phenomena associated with transport and dispersion of chemicals in the atmosphere. At the time of our original analysis, ISC3 was the EPA's preferred dispersion model for short-range releases over flat terrain (up to 50 kilometres), and this was our chosen model. Today ISC3 is listed as "alternative model" (http://www.epa.gov/ttn/scram/dispersion_alt.htm).

\section{Incident review and emission calculations}

Monsanto produces ammonia by reacting Hydrogen with Nitrogen in an Ammonia Converter. At the time of the incident, a Monsanto employee was working on a line valve connected to the Converter. Subsequently, the line ruptured and the contents of the Converter were released horizontally into the atmosphere. The release was a mixture of several gases, but ammonia was the chemical of concern.

Within approximately 2 minutes, Monsanto operators isolated the ammonia line from the rest of the plant, and gas from the Converter continued to flow from the broken line for about 2 hours. During that time, Monsanto personnel sprayed water on the release to wash out some of the ammonia in the gas.

Due to the small pipe diameter and the high pressure inside the Converter, the ammonia gas escaped as a choked-flow horizontal jet. As a result, the gas velocity leaving the pipe was constant at the speed of sound (about 2,170 feet per second or $660 \mathrm{~m} / \mathrm{s}$ ) for much of the leak period [1].

Gas temperature sharply decreases during choked-flow, and in this case the estimated temperature drop is about $185^{\circ} \mathrm{F}$ in the pipe [1]. However, when the gas leaves the pipe and expands, it is diluted with surrounding air and quickly reaches ambient temperature. This initial expansion to ambient temperature created a cloud with an estimated volume of $125 \mathrm{~m}^{3}$ using empirical models $[2,3]$. 
Using data provided by Monsanto and formulas for choked-flow [1, 4], the emission rate for ammonia was calculated and is summarized in Figure 1. The sharp drop in the ammonia release rate occurred after the operators isolated the ammonia line. Figure 1 shows that it took about 2 hours (124 minutes) for the system to release all of the ammonia and leak down to atmospheric pressure (i.e. $0 \mathrm{psig}$ ). The total ammonia release to the atmosphere was estimated to be 2,227 lbs. This is conservative (i.e. an overestimate) because some ammonia was removed by the sprayed water, and also some ammonia remained in the Converter after the system reached atmospheric pressure.

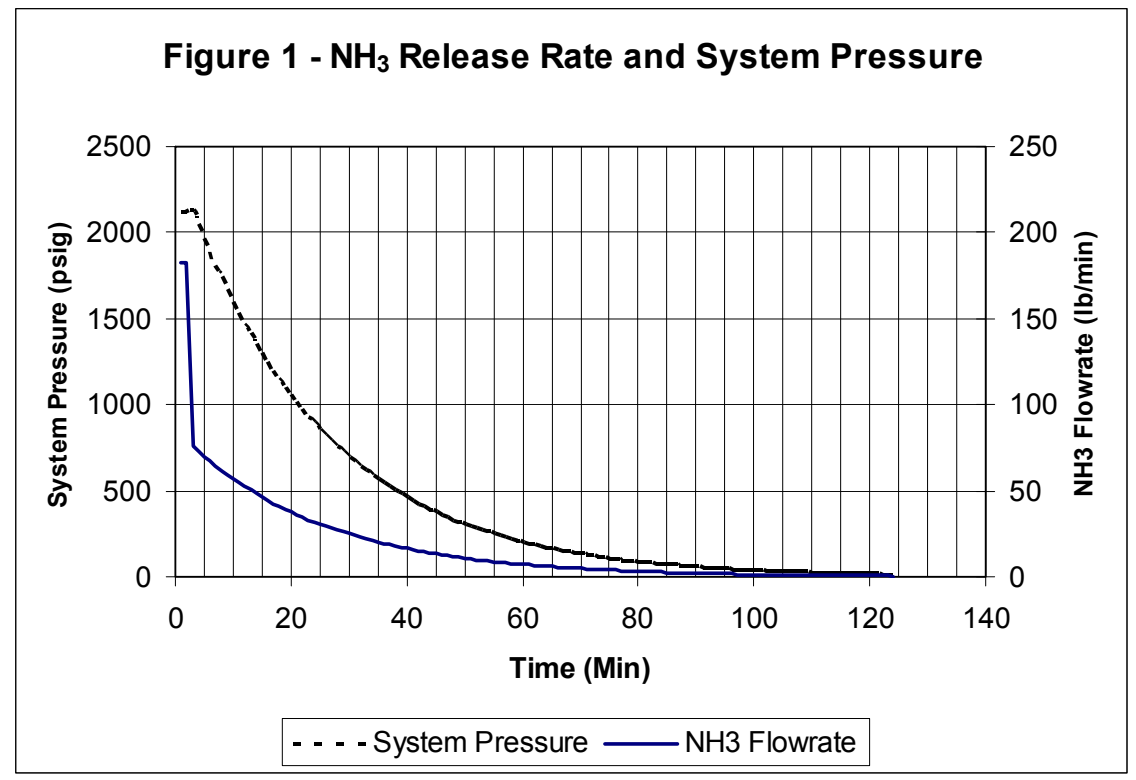

Figure 1: Ammonia release rate and system pressure.

\section{Local weather conditions for air dispersion calculations}

September 1998 was a very warm and wet month for Louisiana. This month was Louisiana's 7th warmest September from 1895-1998 [5] and several tropical storms and hurricanes affected the state during this time. A tropical depression that formed in the Gulf of Mexico on September 17th strengthened to tropical storm Hermine on the morning of the 18th [6]. Hermine transported warm Gulf moisture to southern Louisiana, which developed into rain and thunderstorms.

The three closest available meteorological stations to Monsanto were the following:

1. New Orleans International Airport (MSY);

2. Slidell Airport (6R0);

3. Monsanto's onsite station (MIDAS). 
Figure 2 shows the locations of these stations.

Data from MSY and MIDAS characterize meteorological conditions near the surface, while data from 6R0 gives a vertical profile of the regional atmosphere. Both types of data are needed to accurately model plume dispersion. Trinity Consultants [7] collected the data from MSY and 6R0 and processed it into a format ("ISC-ready" format) suitable for plume modeling.

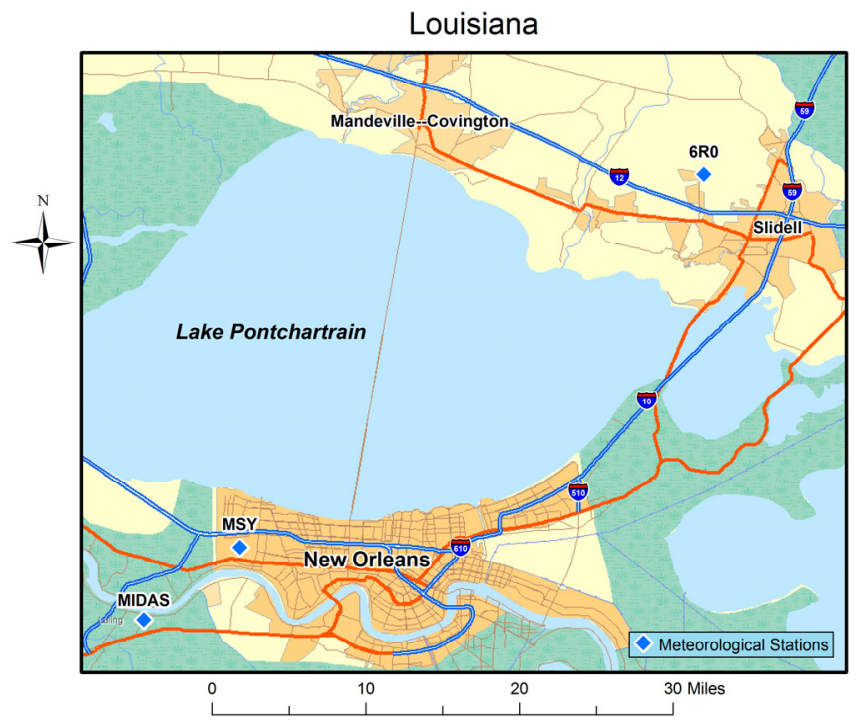

Figure 2: $\quad$ Local meteorological stations.

Figures 3 and 4 show the wind speeds and directions, respectively, for both MSY and MIDAS stations. MIDAS recorded data every five minutes while MSY recorded data once or a few times per hour, so MIDAS provides a more complete record of local conditions. The figures show significant variations in wind over time and also between the two weather stations, which was caused by thunderstorms passing through the area.

To have the best available meteorological characterization for plume modeling, we used the summary of MSY and 6R0 data from Trinity Consultants, but substituted the wind speed, wind direction, and temperature with the onsite MIDAS data from Monsanto [4]. In our opinion, this was the most accurate representation of that morning's weather for modeling plume dispersion in the Monsanto area. Table 1 summarizes the meteorological data that were used for plume modeling. The stabilities and mixing heights were derived from MSY and 6R0 data, and the other variables came from onsite MIDAS data. 


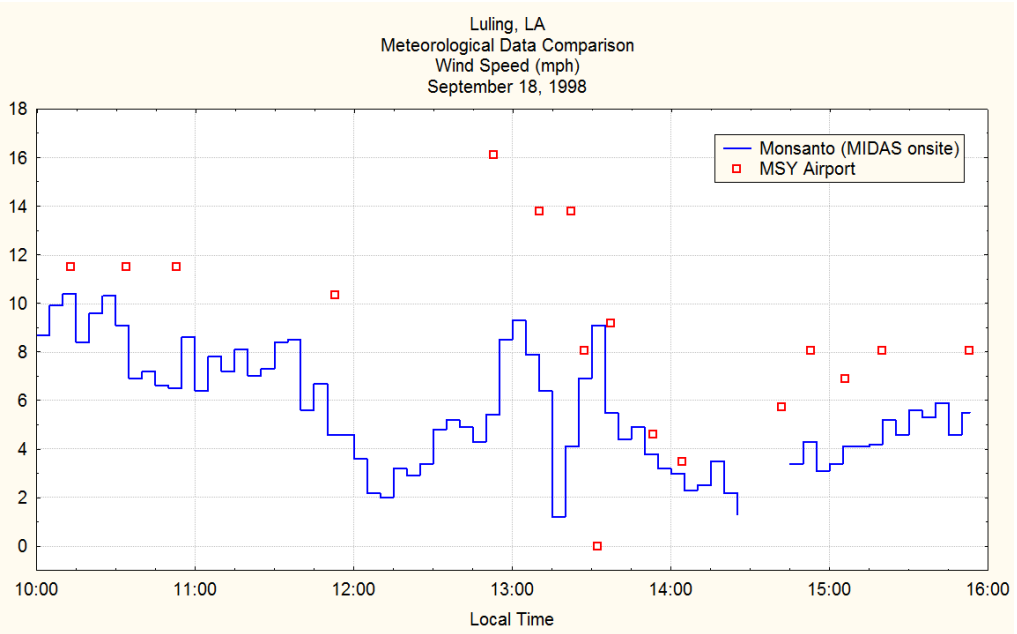

Figure 3: $\quad$ Local wind speeds.

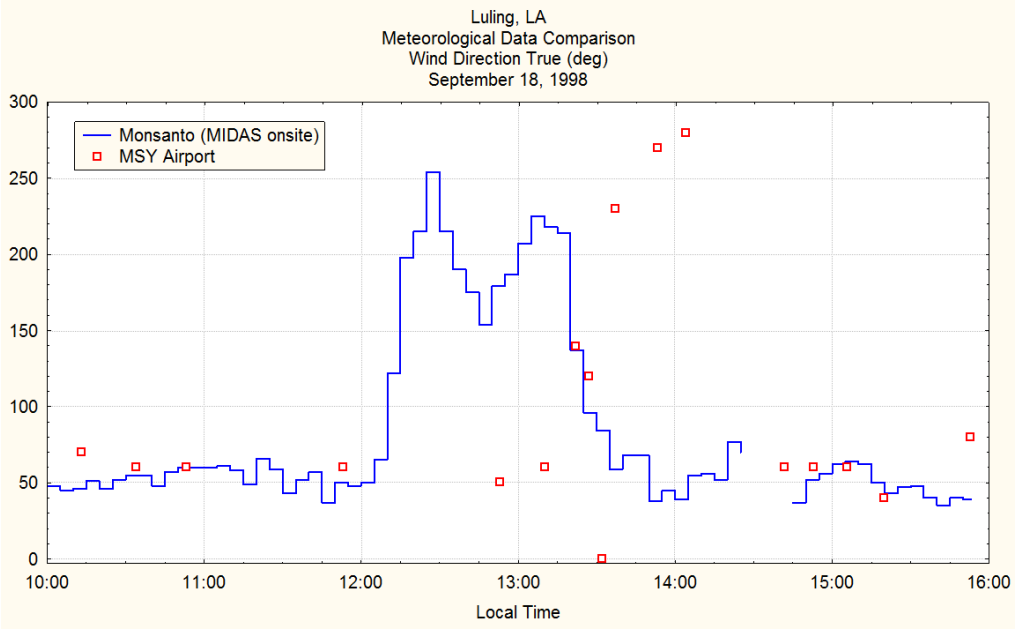

Figure 4: $\quad$ Local wind directions. 
Table 1: $\quad$ Meteorological data used for plume modeling.

\begin{tabular}{|c|c|c|c|c|c|c|}
\hline $\begin{array}{c}\text { Hour } \\
\text { (Local } \\
\text { Time) }\end{array}$ & $\begin{array}{c}\text { Wind Flow } \\
\text { (towards) } \\
\text { (degrees) } \\
\text { (MIDAS) }\end{array}$ & $\begin{array}{c}\text { Wind Speed } \\
\text { (m/s) (MIDAS) }\end{array}$ & $\begin{array}{c}\text { Temperature (K) } \\
\text { (MIDAS) }\end{array}$ & $\begin{array}{c}\text { Stability } \\
\text { Class } \\
\text { (MSY-6R0) }\end{array}$ & $\begin{array}{c}\text { Rural } \\
\text { Mixing } \\
\text { Height (m) } \\
\text { (MSY-6R0) }\end{array}$ & $\begin{array}{c}\text { Urban } \\
\text { Mixing } \\
\text { Height (m) } \\
\text { (MSY- } \\
6 \text { R0) }\end{array}$ \\
\hline $\begin{array}{c}1 \\
(10: 38 \mathrm{AM} \\
\text { to } 11: 38 \\
\mathrm{AM})\end{array}$ & 236 & 3.3 & 300 & 4 & 331.3 & 824.7 \\
\hline $\begin{array}{c}2 \\
(11: 38 \mathrm{AM} \\
\text { to } 12: 38 \\
\text { PM) }\end{array}$ & 294 & 1.9 & 303 & 3 & 410.7 & 780.8 \\
\hline
\end{tabular}

\section{Air dispersion calculations}

Using the emission and meteorological data discussed above, we ran a dispersion model to simulate the atmospheric concentration of ammonia generated in the area by the accidental release.

We selected the Industrial Source Complex (ISC3) model [8] and ran it using the graphical user interface ISC-AERMOD VIEW provided by Lakes Environmental Software of Ontario, Canada. This model has been tested, calibrated, and validated during numerous field experiments and has been used by scientists and organizations throughout the world. This model is very suitable for simulating point, area, or volume sources and computing the concentration generated in the downwind regions. Concentrations are simulated as a series of steady-state hourly averages.

Figures 5 and 6 present the results of the 2-hour ISC3 simulation of the accidental release. Figure 5 shows the average concentration between 10:38 AM and 11:38 AM, and Figure 6 between 11:38 AM and 12:38 PM.

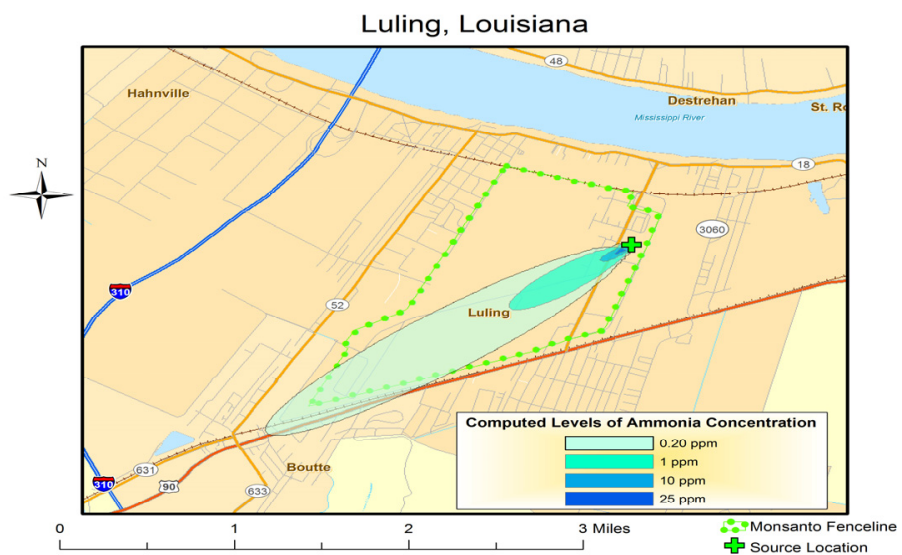

Figure 5: Computed levels of ammonia concentration, 10:38 AM to 11:38 AM, September 18, 1998. 


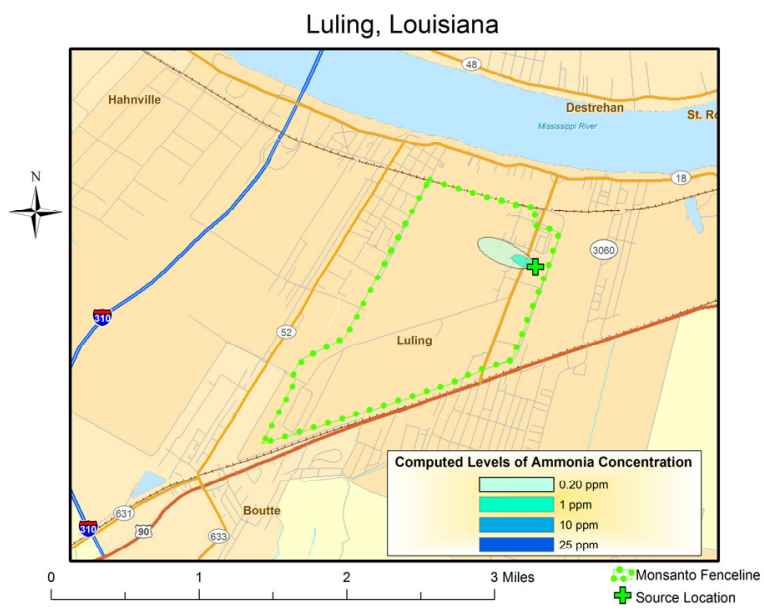

Figure 6: Computed levels of ammonia concentration, 11:38 AM to 12:38 PM, September 18, 1998.

The contour lines in the figures are defined as follows: each contour line encircles an area inside which the one-hour average concentration exceeds the corresponding contour value. The lowest contour value shown in the figures is $0.20 \mathrm{ppm}$ of $\mathrm{NH}_{3}-$ a level which can be used, as discussed in the next section, as a threshold level for possible odor perception.

\section{Discussion of results}

Simulated concentrations should be compared with appropriate Levels of Concern (LOC) to ascertain whether or not the accidental release could have caused adverse effects in the community. As a reference for the simulated concentrations, we used the Emergency Response Planning Guideline (ERPG), which has established well-accepted 1-hour average levels of concern for a large number of chemicals [9].

As shown in Figure 5, the lowest ERPG value - the ERPG-1 value of $25 \mathrm{ppm}$ for $\mathrm{NH}_{3}$ - is only exceeded in a small region close to the source. In the community, outside the Monsanto's fenceline, ammonia concentrations are 100 times (or more) lower than the lowest ERPG value.

The concentrations presented in Figures 5 and 6 are 1-hour average concentrations and are suitable for comparison with 1-hour average ERPG levels. However, short-term concentrations (e.g. 1-minute average concentrations) can be very different from the values shown in Figures 5 and 6. In fact, air quality measurements and atmospheric turbulence theory show that short-term concentrations do not remain constant and generally fluctuate above and below the hourly average.

Odor perceptions are caused by short-term concentrations (e.g., 1-minute average concentrations). Formulas are available in the literature to estimate the 
maximum short-term concentration during the hour from the hourly average value (i.e., a "peak-to-mean ratio"). For example, the formula below [10] has been used by several scientists, and is described by the Commonwealth Scientific and Industrial Research Organization (CSIRO):

$$
\frac{C_{T 1}}{C_{T 2}}=\left(\frac{T 1}{T 2}\right)^{-0.35}
$$

where, for example, if $\mathrm{T} 2=60$ minutes and $\mathrm{T} 1=1$ minute, the formula says that the peak 1-minute average concentration $\mathrm{C}_{\mathrm{T} 1}$ during a 60 -minute period is equal to 4.2 times the 60 -minute average concentration $\mathrm{C}_{\mathrm{T} 2}$.

Moreover, Figure 1 shows that the initial emission rate in the first few minutes of the release is higher (2-to-6 times higher) than the hourly average emission rate. Therefore, people affected at the beginning of the incident should have experienced short-term concentrations that were 2-to-6 times higher than the average values depicted in Figures 5 and 6.

In conclusion, based upon the above discussion, the hourly average concentrations should be multiplied by 4.2 and by a number between 2 and 6 , in order to represent the maximum, worst-case 1-minute concentration to characterize possible odor perception. Therefore, the 1-hour average $0.20 \mathrm{ppm}$ contour line in Figure 5 actually represents a potential value of 2-to-5 ppm of ammonia, for a maximum, worst-case 1-minute exposure - a value at which sensitive people may experience an odor sensation.

Figure 7 shows the modeling results for the first hour (10:38 AM-11:38 AM) along with plaintiff and complaint locations, which include the Boutte Christian

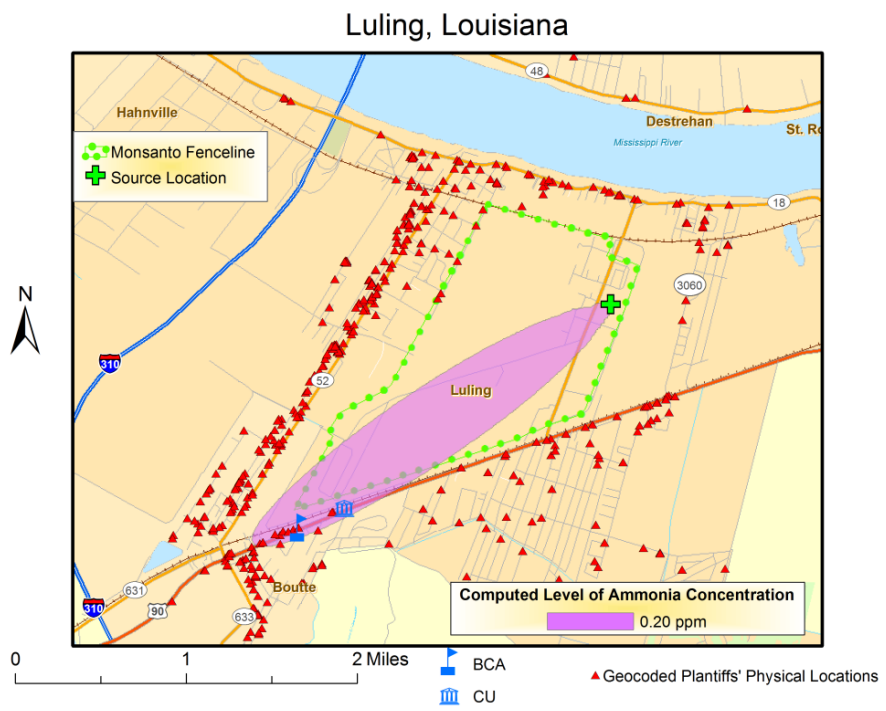

Figure 7: Modeling results for the first hour (10:38 AM-11:38 AM) along with plaintiff and complaint locations. 
Academy (BCA) and the Credit Union (CU). The concentrations computed by the ISC3 model are in agreement with the record of complaints made to Monsanto on the day of the incident and $\mathrm{NH}_{3}$ monitoring performed by Monsanto technicians. In fact, a complaint at the Boutte Christian Academy (BCA) mentions an ammonia odor from 11:10 AM to 11:20 AM. The BCA location is at the plume centerline 2.5 miles away from the release. The wind is blowing at about 7 miles per hour and therefore this complaint reasonably matches the modeling results in location and time.

It should be noted that the wind direction is blowing directly from the source of the release toward the BCA location from 10:38 AM to 12:10 PM. Yet, the odor complaint ends at 11:20 AM. This confirms that only at the beginning of the incident (e.g., the first 10 minutes) does the ammonia emission have enough strength to cause a small odor perception in the community.

The fact that ammonia concentrations are low at BCA is further confirmed by the Drager Tube sample collected at 11:15 AM showing a non-zero concentration of ammonia below $5 \mathrm{ppm}$. This sample was taken at the center of the plume and yet the concentration is practically negligible.

A faint odor of ammonia was also reported at 11:15 AM by a person parked at the Credit Union (CU). Again, a non-zero concentration of ammonia below 5 ppm was measured at the site using a Drager Tube.

As shown in Figure 7, these two locations (BCA and $\mathrm{CU}$ ) are directly downwind the release and, therefore, are the locations in the community where the maximum concentration impact is expected. The lack of other contemporaneous odor complaints and the non-zero measurements taken at other locations confirm that the plume trajectory affected a very limited area, in agreement with the modeling results.

During the second hour of the release, the wind direction varies. However, the high-resolution 5-minute wind data collected at the Monsanto MIDAS station indicate that the wind flow remained almost constant (blowing from the location of the release directly towards BCA and CU) until 12:10 PM. After this time the emission from the release is practically negligible, as shown in Figure 1. Therefore, both the air pollution modeling calculations and the evidence of contemporaneous odor complaints and ammonia measurements show that the only plume impact (a short, faint ammonia odor) in the community was experienced around BCA and CU between 11:10 AM and 11:20 AM, at the time and location where the initial, larger release of the first few minutes (e.g., 10:38 AM to 10:48 AM) is expected to have caused the highest impact.

Along with our ISC3 modeling results, we produced a MONTECARLO [11] animation showing how the ammonia plume traveled from the line rupture to the community in real time. Figure 8 shows an animation frame of the simulated particles. This animation used the onsite MIDAS wind data and agrees closely with the timing and locations of odor complaints in the community. The full animation, with different colors representing concentrations, can be examined at http://envirocomp.com/caps/projects/monsanto/v1.html. 


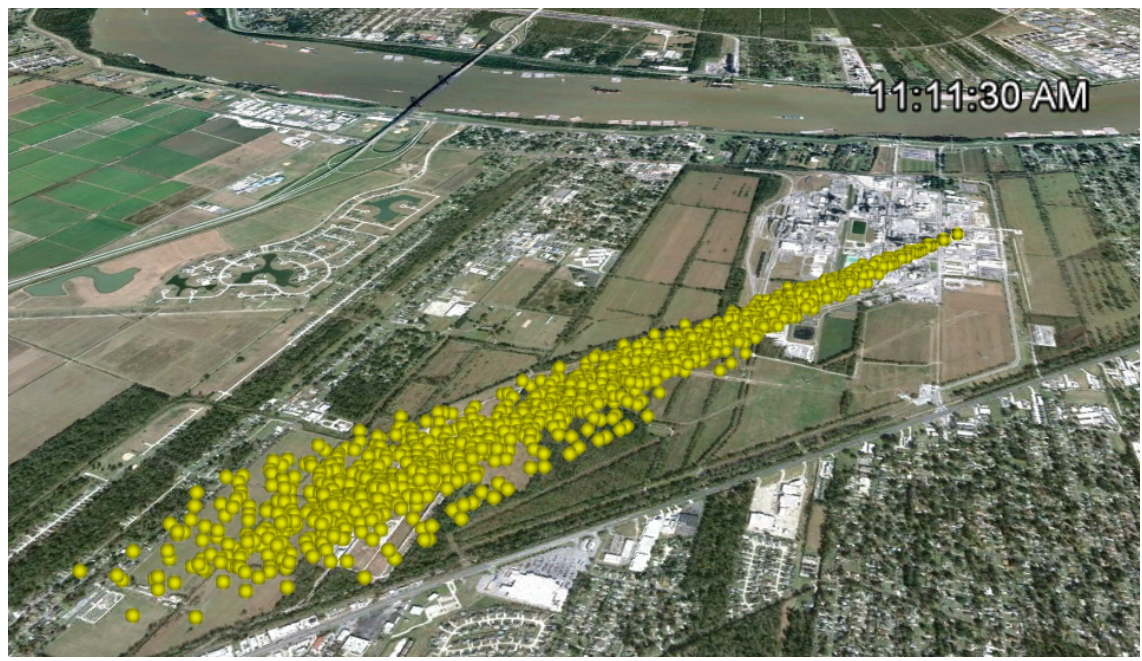

Figure 8: Modeling results using MONTECARLO particles for the plume (animation frame).

\section{Summary and conclusions}

About 2,227 pounds of gaseous ammonia were released from the Monsanto Plant in Luling, Louisiana from 10:38 AM to 12:38 AM on September 18, 1998. This gaseous release was simulated by the ISC 3 dispersion model after calculating an emission timeline and identifying local weather conditions.

We found that the concentration levels of ammonia in the community had an hourly concentration of $0.20 \mathrm{ppm}$ or less, with a short-term peak of possibly 5 ppm. These values are well below any published level of concern for human health. Based on our simulation results, local measurements, and odor complaints, we concluded that a relatively small number of people could be affected by the plume and these people may have experienced a brief, faint odor sensation during the incident.

\section{References}

[1] Perry, R.H. and Green, D.W., Perry's Chemical Engineers' Handbook, 7th Edition, McGraw-Hill: 1997.

[2] Ignatius, T. J. and Rathakrishnan, E., Similarity Scales for Free and Impinging Jet Flow Fields. High Speed Jet Flows, FED-Vol. 214, ASME: 1995.

[3] Panda, J. and Seasholtz, R. G., Velocity and Temperature Measurement in Supersonic Free Jets Using Spectrally Resolved Rayleigh Scattering, NASA TM 2003-212391, 2003.

[4] Monsanto Corporation Counsel, Personal Communications, 2003-2004. 
[5] NOAA National Climatic Data Center Temperature Map Online. http://www.ncdc.noaa.gov/img/climate/research/1998/sep/SepmapC Pg.gif NCDC Storm Record Details Online. http://www.ncdc.noaa.gov /stormevents/ftp.jsp

Trinity Consultants, Personal Communication, 2003-2004. http://www.trinityconsultants.com

[6] ISC3 Model Information Online. http://www.epa.gov/ttn/scram /dispersion alt.htm\#isc3

[7] ERPG Values Online. http://www.stb07.com/technical-safety/emergencyresponse-planning-guidelines.html

[8] CSIRO Air Quality Peak-to-Mean Calculator Online. http://www.cmar. csiro.au/airquality/peaktomean.html

[9] Zannetti, P. and Sire, R. MONTECARLO - A New, Fully-Integrated PC Software for the 3D Simulation and Visualization of Air Pollution Dispersion Using Monte Carlo Lagrangian Particle (MCLP) Techniques. Air Pollution 99, Stanford, California. WIT Publications: Ashurst, UK, July 1999. http://www.envirocomp.com/zcv/P.47.pdf 